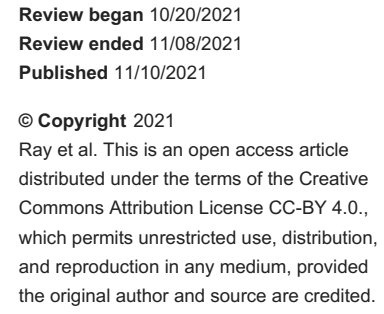

\section{Pancreatic Lymphangioma: An Unusual Cause of Abdominal Lump}

\author{
Rubik Ray ${ }^{1}$, Tridip Dutta Baruah ${ }^{1}$, Hari Shankar Mahobia ${ }^{1}$, Akshay Borkar ${ }^{1}$ \\ 1. General Surgery, All India Institute of Medical Sciences, Raipur, IND
}

Corresponding author: Tridip Dutta Baruah, tridipduttabaruah@gmail.com

\begin{abstract}
Lymphangiomas are uncommon benign malformations that can occur anywhere in the body. These are hamartomatous malformations with lymphatic differentiation, which uncommonly involve the abdomen and rarely the pancreas.
\end{abstract}

The size of the cysts in pancreatic lymphangioma directly correlates with the clinical manifestations; however, most of them are non-specific. Preoperative diagnosis is challenging because conventional imaging examinations like an abdominal ultrasonogram (USG), computed tomography, or magnetic resonance imaging cannot distinguish pseudocyst, mucinous cyst neoplasms, simple cyst, intraductal papillary mucinous neoplasms, and serous cystadenoma.

We are presenting a rare case of pancreatic lymphangioma where the definitive diagnosis was made postoperatively in histopathological examination. A female patient aged 27 years presented to the Surgery outpatient department with a slow-growing abdominal lump of 9 months duration. Clinical examination revealed large, non-tender, soft cystic swelling occupying the entire upper abdomen. Radiological imaging showed a large multiseptated cystic lesion occupying almost the entire abdomen and adhered to the pancreas with mass effect. USG-guided fine-needle aspiration revealed straw-colored aspirate with mature lymphocytes.

On exploration, there was a large multiloculated cyst occupying the whole abdomen. Cysts were decompressed, and the entire lesion was excised. Final histopathological examination showed unremarkable pancreatic tissue with attached lesion consisting of dilated lymphatic spaces with lymphatic follicles.

Categories: Internal Medicine, Radiology, General Surgery

Keywords: pseudocyst, endoscopic ultrasound, pancreatic cystic lesion, benign, lymphangiomas

\section{Introduction}

Lymphangiomas are benign malformations of vascular origin with lymphatic differentiation, most commonly encountered in the head and neck region. These hamartomatous malformations uncommonly involve the abdomen and rarely the pancreas.

Pancreatic lymphangiomas are very uncommon, accounting for only $1 \%$ of abdominal lymphangiomas and less than $0.5 \%$ of all cystic pancreatic lesions. No more than 100 cases are reported in the literature $[1,2]$.

These tumors result from lymphangiectasias as a consequence of a blockage of lymphatic flow. This may be associated with congenital malformations or obstructions as a result of an inflammatory process, radiotherapy, surgery, or any abdominal trauma.

Preoperative diagnosis of pancreatic lymphangioma is difficult, and the majority are diagnosed after surgery. Most of the radiological investigations are non-specific; however, with endoscopic ultrasound (EUS), a certain preoperative diagnosis is possible.

Morphologic features on ultrasonography with biochemical and cytological characteristics of the cyst fluid obtained by EUS-guided fine-needle aspiration (FNA) can aid in the diagnosis [3,4].

\section{Case Presentation}

A female patient aged 27 years presented with a slow-growing abdominal lump of nine months duration. There were no other symptoms except for fullness of the abdomen after taking food and weight loss. Clinical examination revealed large, non-tender, soft cystic swelling occupying the entire upper abdomen.

On radiological investigations, ultrasonogram (USG)-complex cystic mass with internal septation was present. Contrast-enhanced computed tomography (CECT) abdomen showed a large multiseptated cystic 


\section{Cureus}

lesion occupying almost the entire abdomen and adhered to the pancreas with mass effect. The lesion was well defined, lobulated, hypodense in nature, and associated with main pancreatic duct dilatation. There was also portal vein thrombosis with portal cavernoma on the CECT abdomen (Figure 1).

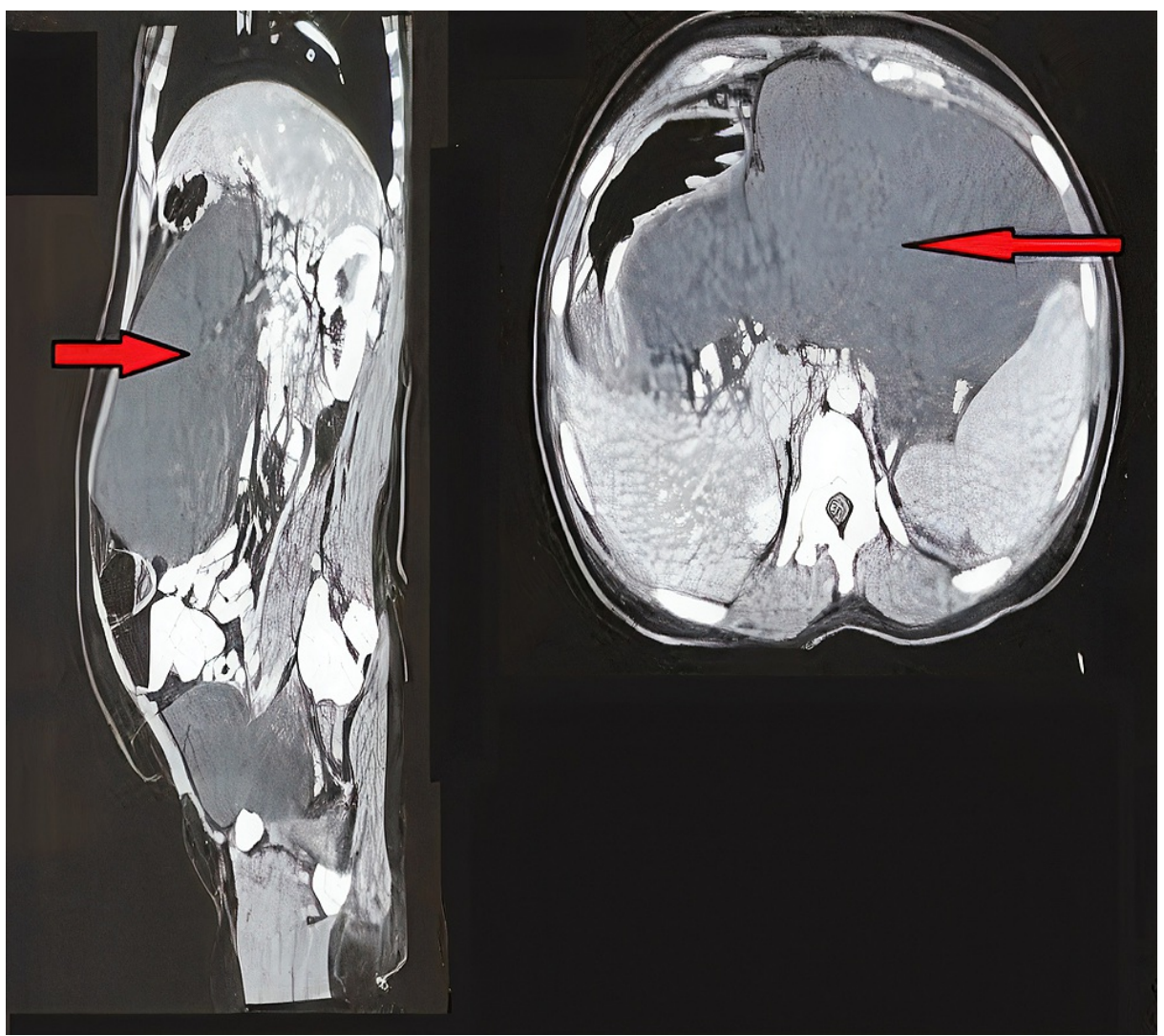

FIGURE 1: CECT abdomen showed large multiseptated cystic lesion occupying almost the entire abdomen and adhered to pancreas with mass effect. Lesion was well defined, lobulated, and hypodense in nature.

CECT, contrast-enhanced computed tomography.

USG-guided FNAC revealed straw-colored aspirate with mature lymphocytes; no atypical cells were noted. Cyst amylase and carcinoembryonic antigen (CEA) were within the normal range (Figure 2). 


\section{Cureus}

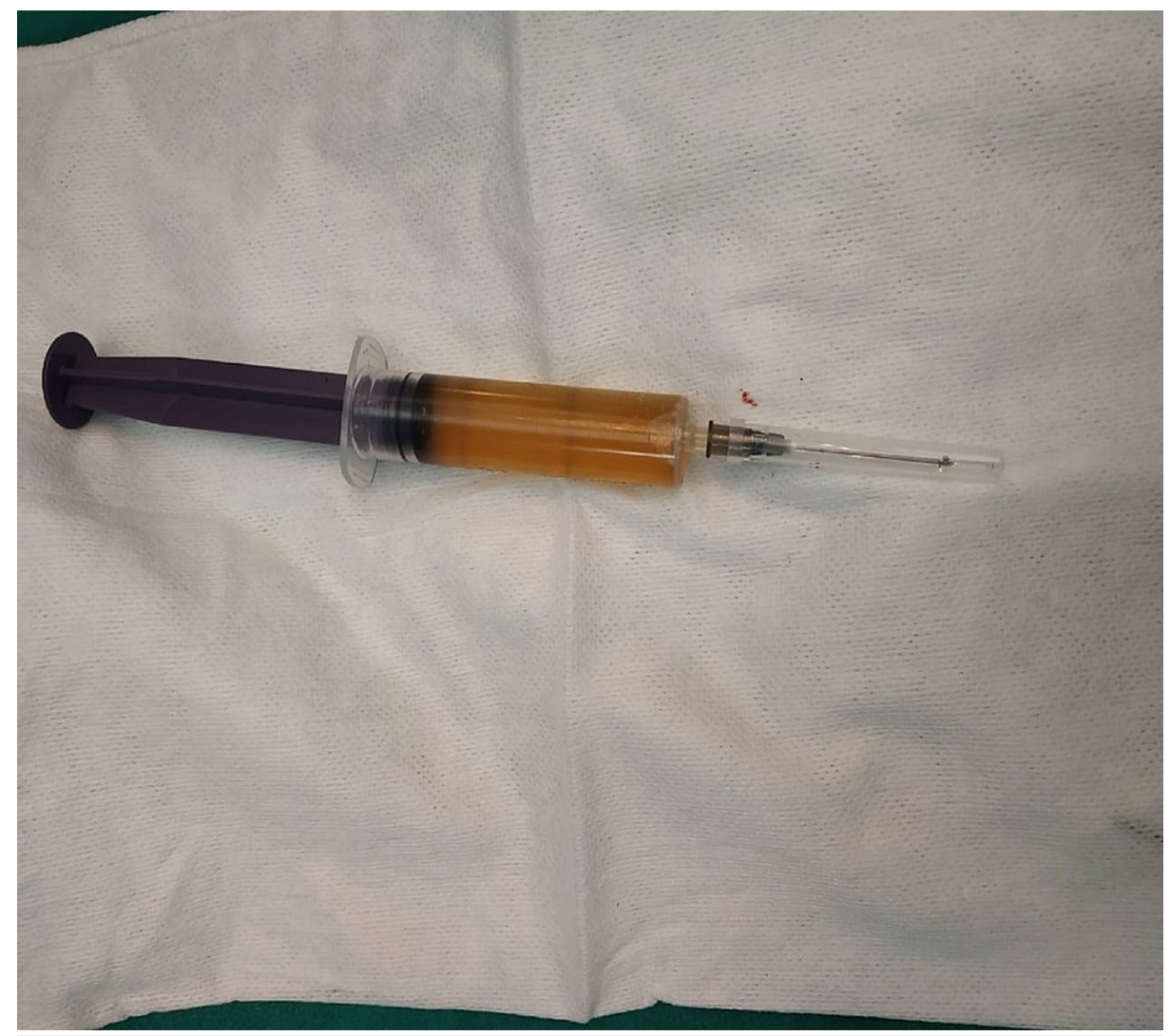

FIGURE 2: Straw-colored aspirated fluid sent for biochemical and cytological examination.

After complete preoperative workup, the patient underwent surgical exploration. On exploration, there was a large multiloculated cystic lesion extending through gastrocolic omentum, pushing the stomach up and transverse colon downwards with hundreds of cystic spaces containing lymphatic fluid (Figure 3). 


\section{Cureus}

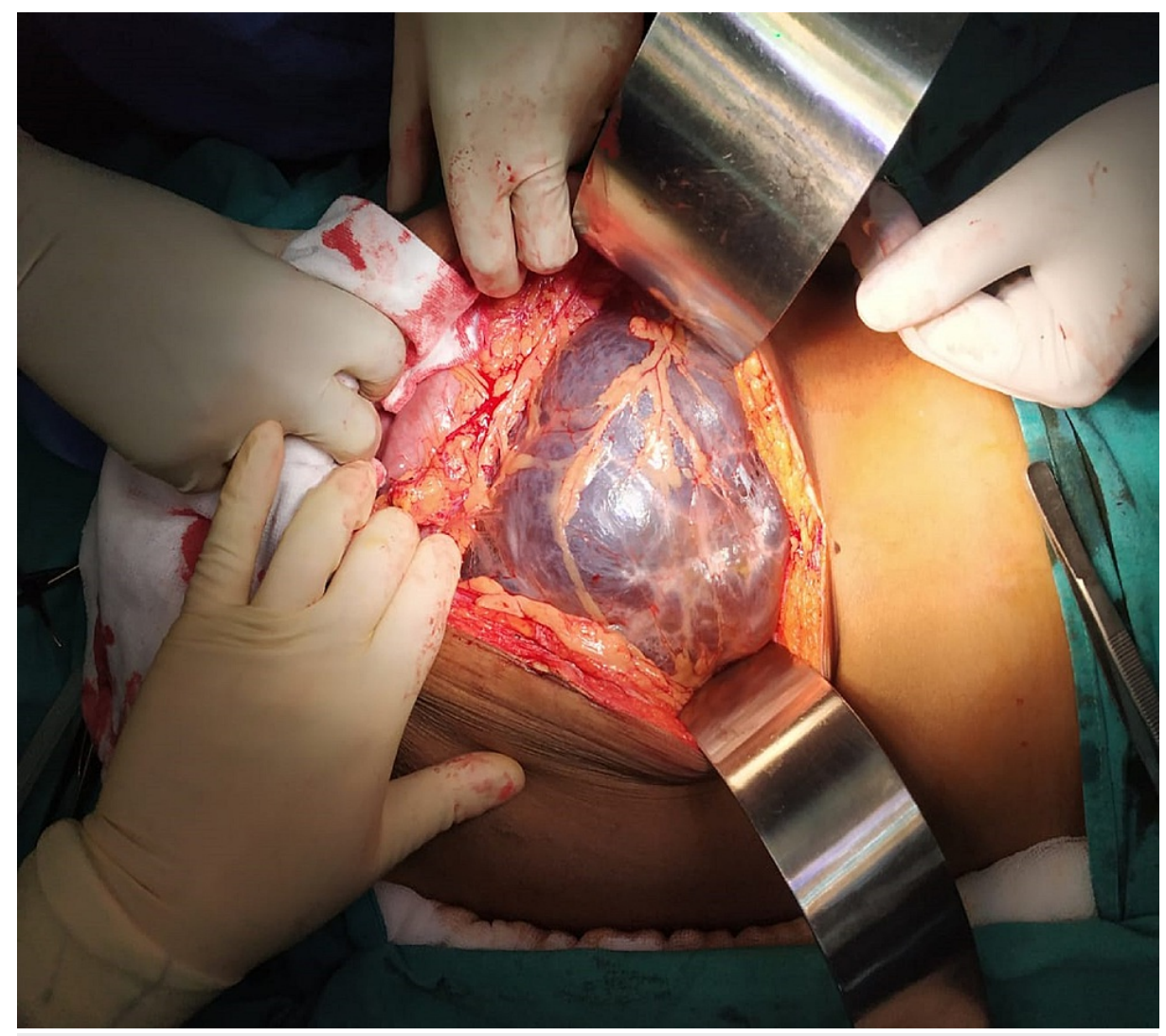

FIGURE 3: Large thin-walled, multiseptated cyst occupying whole of the abdomen.

Cysts were decompressed, and the entire lesion was excised. The anterior surface of the pancreas was forming the base of the lesion. Postoperatively patient had continued lymphatic discharge from the abdominal drain, and the patient was discharged with it (Figure 4). 


\section{Cureus}

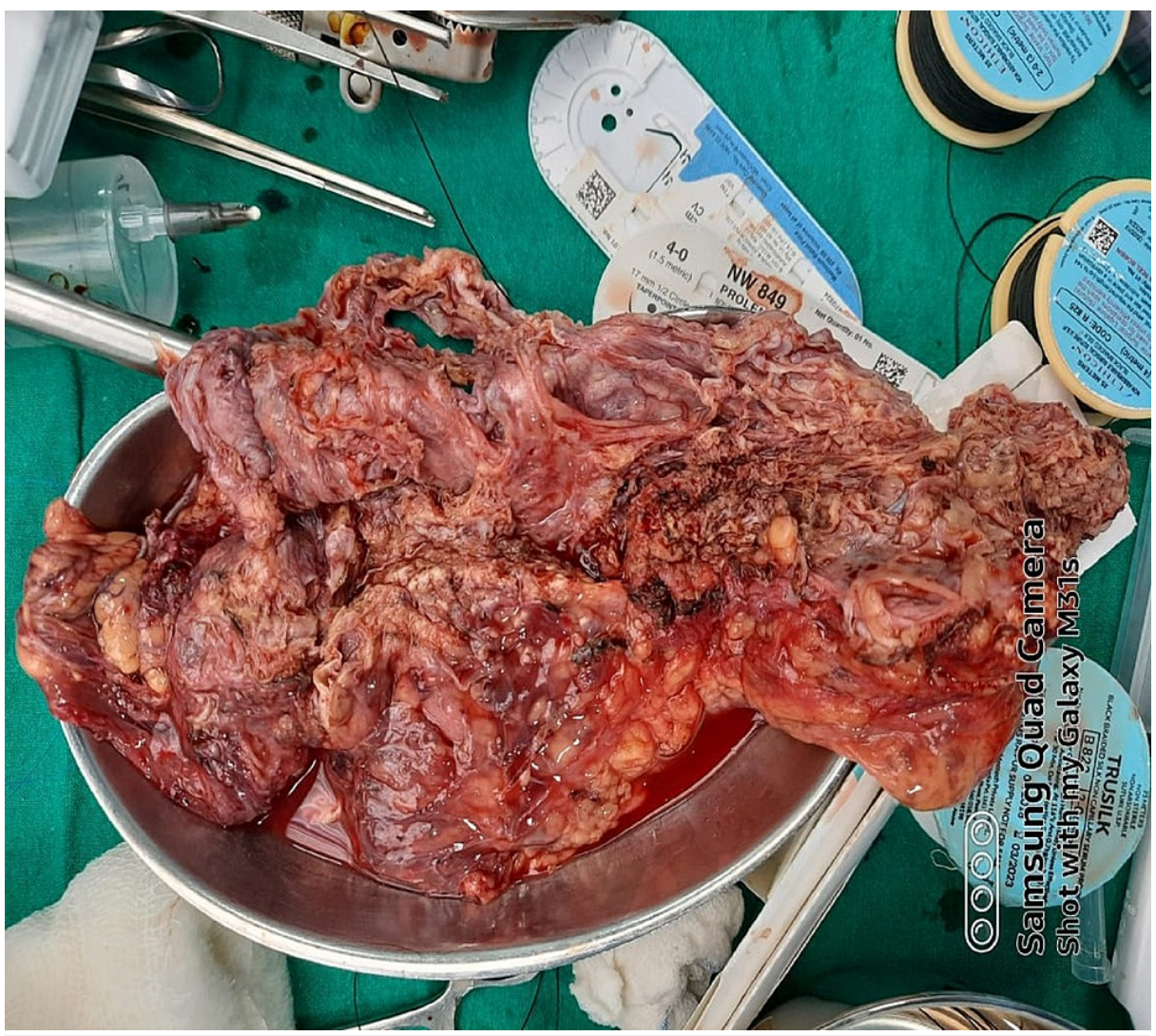

FIGURE 4: Complete resected specimen of multiseptated cyst after aspiration.

Final histopathological examination showed unremarkable pancreatic tissue with attached lesion consisting of dilated lymphatic spaces with lymphatic follicles in the wall, with congested blood vessels and fibrocollagenous tissue with chronic inflammatory infiltrate. Cytocentrifuged smears from fluid show lymphocytes, and no malignant or atypical cell was seen. The patient was followed regularly in outpatient department, and drain output gradually decreased over two weeks and was removed (Figure 5). 


\section{Cureus}

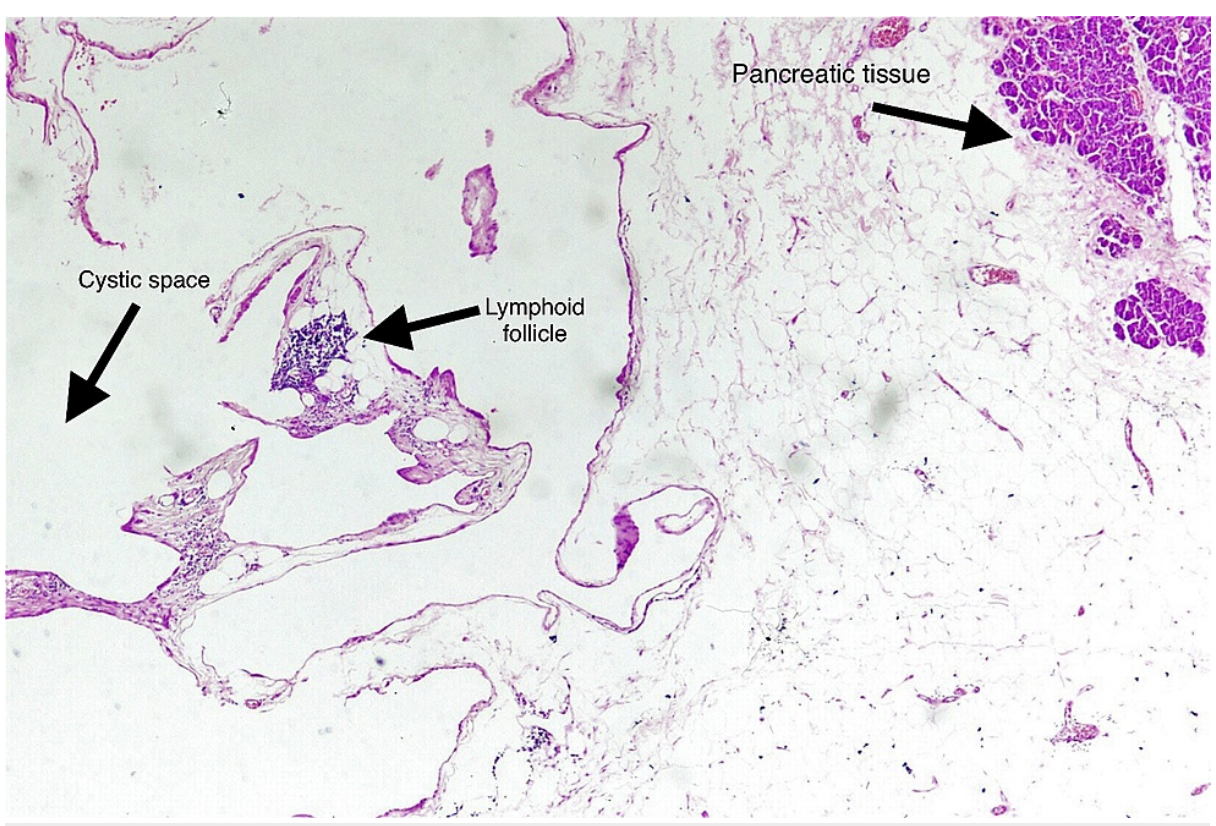

FIGURE 5: Photomicrograph illustrating pancreatic tissue with attached lesion composed of dilated lymphatic spaces with lymphoid follicles in the wall (H\&E, x4).

\section{Discussion}

Lymphangiomas are indolent, benign tumors that arise as a consequence of congenital lymphatic malformations or lymphangiectasis [5]. Pancreatic lymphangioma is a rare cause of abdominal lump, accounting for less than 100 cases described in the literature [2]. It was first reported by Koch in 1913 [6]. These tumors are often seen in the pancreatic body or tail, although they can also arise from the rest of the gland [7].

Pancreatic lymphangioma is primarily asymptomatic and is usually discovered incidentally in the radiological investigation [3]. When increased in size, they can become symptomatic and commonly present as a palpable abdominal mass and abdominal pain, which may sometimes be associated with nausea and vomiting due to pressure effects [8]. Erguney et al. and Schneider et al. reported that the most common symptom in their case was palpable abdominal mass $[9,10]$. Palpable abdominal mass with nausea and vomiting due to pressure effect was the presentation in our case also. Uncommonly it may present as an acute abdomen due to intracystic bleeding, infection, cyst rupture, and volvulus [11]. Differential diagnoses include simple cyst, pseudocyst, cystadenoma, and cystadenocarcinoma [12].

In our patient, the preoperative diagnosis was challenging because radiological studies were insufficient to diagnose the lesion and the facility of EUS was not available. There are also no specific or significant laboratory investigations that can confirm or aid in diagnosing pancreatic lymphangioma [13]. The mass on imaging USG appears as a complex cystic lesion, which is separated with internal septa and internal echoes. On CECT, it appears as a thin-walled, low-density homogeneous, well-circumscribed mass that may be unilocular or multilocular with thin-enhancing endocytic septae. These radiological features mimic cystadenomas that are far more frequent in the pancreas [14]. On MRI, the lesion appears hypointense on $\mathrm{T} 1$ sequence and hyperintense on T2. MRI when compared to CT is also superior in excluding communication between the cystic lesion and pancreatic duct [15].

As per recent literature, EUS with FNA is the preferred investigation for diagnosis. Fluid cytology with biochemical markers in combination with morphological features by EUS can aid in achieving a definitive diagnosis preoperatively [16-18]. We preferred USG-guided FNA as the cyst was superficial. However, CTguided FNA can also be done depending on the site of the cyst.

On aspiration, the content can be straw-colored or frank chylous with a high triglyceride level in the case of an abdominal lymphangioma [3,19]. The measure of amylase and CEA are unremarkable and are of no value in these types of cysts [20]. The diagnosis of lymphangioma can also be validated pathologically: a thin septum separating the cyst spaces, composed of mature lymphocytes, smooth muscle cells, and some histiocytes, which are pathological hallmarks in the diagnosis of these lesions. The aspirated fluid on cytological examination also shows a high population of small mature lymphocytes [5]. On immunohistochemistry, CD31, CD34, and factor VIII-R are positive and are markers for lymphatic and 
capillary endothelial cells [19].

The treatment is dictated by the size and location of the lesion. Carvalho et al. considered that lymphangiomas are benign lesions; a conservative approach with regular watchful observation is acceptable and is logical if a definitive diagnosis is already made by EUS [2]. However, other works of literature advocate that surgical excision performed in its entirety is the treatment of choice and curative [19]. The patient may need a simple excision of the mass to extensive pancreatic resections, such as a Whipple procedure or distal pancreatectomy, depending on the site and size of the lesion [21].

\section{Conclusions}

Pancreatic lymphangioma is ordinarily asymptomatic and is usually discovered incidentally. Pancreatic lymphangiomas are uncommon lesions presenting as an abdominal mass. However, sometimes it may also present with nausea, vomiting, and weight loss in addition to the mass abdomen as a result of pressure effects.

Diagnosis of pancreatic lymphangioma is challenging as most radiological investigations are non-specific; however, EUS-guided FNA with cyst fluid analysis can confirm the diagnosis. Cytological examination with immunohistochemistry should be done where facilities are available to enable an accurate preoperative diagnosis and plan treatment.

Few literature has advocated a conservative approach with watchful observation; however, a surgical excision performed in its entirety is preferred and is curative in patients presenting with mass effects.

\section{Additional Information \\ Disclosures}

Human subjects: Consent was obtained or waived by all participants in this study. Not Applicable issued approval Not Applicable. Written informed consent has been taken from the patient prior to the writing of the manuscript and the identity of the patient won't be disclosed at any point in time. Since this is a case report IEC approval is not mandatory; the patient has already consented for his case to be published in any journal. The case had been presented as a poster in CGASICON in the interest to share knowledge among peers. Conflicts of interest: In compliance with the ICMJE uniform disclosure form, all authors declare the following: Payment/services info: All authors have declared that no financial support was received from any organization for the submitted work. Financial relationships: All authors have declared that they have no financial relationships at present or within the previous three years with any organizations that might have an interest in the submitted work. Other relationships: All authors have declared that there are no other relationships or activities that could appear to have influenced the submitted work.

\section{Acknowledgements}

I acknowledge the help provided by Prof (Dr) Nighat Hussain and Dr Kadali Kavya, Department of Pathology, AIIMS Raipur. I also appreciate the great generosity and understanding of Dr Nighat, without which it would have been difficult to complete the article

\section{References}

1. Karajgikar J, Deshmukh S: Pancreatic lymphangioma: a case report and literature review . J Comput Assist Tomogr. 2019, 43:242-4. 10.1097/RCT.0000000000000818

2. Carvalho D, Costa M, Russo P, Simas L, Baptista T, Ramos G: Cystic pancreatic lymphangioma - diagnostic role of endoscopic ultrasound. GE Port J Gastroenterol. 2016, 23:254-8. 10.1016/j.jpge.2016.01.006

3. Coe AW, Evans J, Conway J: Pancreas cystic lymphangioma diagnosed with EUS-FNA . J Pancreas. 2012, 13:282-48.

4. Applebaum B, Cunningham JT: Two cases of cystic lymphangioma of the pancreas: a rare finding in endoscopic ultrasonography. Endoscopy. 2006, 38 Suppl 2:E24-5. 10.1055/s-2006-944645

5. Fahimi H, Faridi M, Gholamin S, Molanaee S, Khorsandi M: Cystic lymphangioma of the pancreas: diagnostic and therapeutic challenges. JOP. 2010, 11:617-9.

6. City PJ, Sansho EU, Lekshmidevi P, Umman P, Varghese S, KurienJS: Giant cystic lymphangioma of pancreas---a rarity. World J Pathol. 2014, 4:72-6.

7. Mortelé KJ: Cystic pancreatic neoplasms: imaging features and management strategy . Semin Roentgenol. 2013, 48:253-63. 10.1053/j.ro.2013.03.006

8. Dalla Bona E, Beltrame V, Blandamura S, Liessi F, Sperti C: Huge cystic lymphangioma of the pancreas mimicking pancreatic cystic neoplasm. Case Rep Med. 2012, 2012:951358. 10.1155/2012/951358

9. Erguney S, Teksoz S, Erdamar S, Ainechii S, Olgun DC: Extended pancreaticoduodenectomy for a huge cystic-cavernous lymphangioma: a case report. JOP. 2012, 13:289-91.

10. Schneider G, Seidel R, Altmeyer K, Remberger K, Pistorius G, Kramann B, Uder M: Lymphangioma of the pancreas and the duodenal wall: MR imaging findings. Eur Radiol. 2001, 11:2232-5. 10.1007/s003300100846

11. Gureș N, Gurluler E, Alim A, Berber I, Gurkan A: Cystic pancreatic lymphangioma. Rare Tumors. 2012, 4:e27. 10.4081/rt.2012.e27

12. Koenig TR, Loyer EM, Whitman GJ, Raymond AK, Charnsangavej C: Cystic lymphangioma of the pancreas. 


\section{Cureus}

AJR Am J Roentgenol. 2001, 177:1090. 10.2214/ajr.177.5.1771090

13. Leung TK, Lee CM, Shen LK, Chen YY: Differential diagnosis of cystic lymphangioma of the pancreas based on imaging features. J Formos Med Assoc. 2006, 105:512-7. 10.1016/S0929-6646(09)60193-5

14. Macin G, Hekimoglu K, Uner H, Tarhan C: Pancreatic cystic lymphangioma: diagnostic approach with MDCT and MR imaging. JBR-BTR. 2014, 97:97-9. 10.5334/jbr-btr.26

15. Afzal S, Masroor I, Shafqat G: Pancreatic lymphangioma. J Coll Physicians Surg Pak. 2014, 24:60-1.

16. Bhatia V, Rastogi A, Saluja SS, Kumar M, Bihari C, Kalayarasan R, Gupta NL: Cystic pancreatic lymphangioma. The first report of a preoperative pathological diagnosis by endoscopic ultrasound-guided cyst aspiration. JOP. 2011, 12:473-6.

17. Hussain I, Ang TL: Cystic pancreatic lymphangioma diagnosed with endoscopic ultrasound-guided fine needle aspiration. Endosc Ultrasound. 2017, 6:136-9. 10.4103/2303-9027.204807

18. Black T, Guy CD, Burbridge RA: Retroperitoneal cystic lymphangioma diagnosed by endoscopic ultrasoundguided fine needle aspiration. Clin Endosc. 2013, 46:595-7. 10.5946/ce.2013.46.5.595

19. Ghatak S, Ray S, Sanyal S, et al.: An usual cause of acute abdomen in adults: giant cystic lymphangioma of the pancreatic head. A clinical case and literature review. J Pancreas. 2011, 12:266-70.

20. Fonseca R, Pitman MB: Lymphangioma of the pancreas: a multimodal approach to pre-operative diagnosis . Cytopathology. 2013, 24:172-6. 10.1111/j.1365-2303.2011.00897.x

21. Paal E, Thompson LD, Heffess CS: A clinicopathologic and immunohistochemical study of ten pancreatic lymphangiomas and a review of the literature. Cancer. 1998, 82:2150-8. 10.1002/(sici)1097

0142(19980601)82:11<2150::aid-cncr9>3.0.co;2-z 